\title{
Hour Times Kilogram per Milliliter
}

National Cancer Institute

\section{Source}

National Cancer Institute. Hour Times Kilogram per Milliliter. NCI Thesaurus. Code C85614.

Hours times kilograms per milliliter. 